\title{
Optimization of electrocoagulation of instant coffee production wastewater using the response surface methodology
}

\author{
Ha Manh Bui* \\ Sai Gon University, Department of Environmental Sciences, Ho Chi Minh City, Vietnam \\ "corresponding author: manhhakg@yahoo.com.vn
}

\begin{abstract}
The COD removal efficiency from an instant coffee processing wastewater using electrocoagulation was investigated. For this purpose, the response surface methodology was employed, using central composing design to optimize three of the most important operating variables, i.e., electrolysis time, current density and initial $\mathrm{pH}$. The results based upon statistical analysis showed that the quadratic models for COD removal were significant at very low probability value $(<0.0001)$ and high coefficient of determination $\left(\mathrm{R}^{2}=0.9621\right)$ value. The statistical results also indicated that all the three variables and the interaction between initial $\mathrm{pH}$ and electrolysis time were significant on COD abatement. The maximum predicted COD removal using the response function reached $93.3 \%$ with electrolysis time of $10 \mathrm{~min}$, current density of $108.3 \mathrm{~A} / \mathrm{m}^{2}$ and initial $\mathrm{pH}$ of 7.0 , respectively. The removal efficiency value was agreed well with the experimental value of COD removal (90.4\%) under the optimum conditions.
\end{abstract}

Keywords: coffee production wastewater, electrocoagulation, optimization, surface response method.

\section{INTRODUCTION}

Instant coffee processing wastewater contains large amounts of macromolecules such as tannins, lignins, or humic acid which causes water pollution. The untreated macromolecules contain the large amount of $\mathrm{COD}^{1}$ that pollutes different type of water resources. Therefore, it is necessary to reduce the pollutant concentration in the wastewater before discharging it into the environment.

Previous studies proved that conventional wastewater treatment method such as coagulation and flocculation could not effectively eliminate the pollutants in coffee processing wastewater ${ }^{2}$ and sometimes the methods could release a huge volume of sludge containing excessive organic polymers which could harm to aquatic organi$\mathrm{sms}^{3}$. Advanced oxidation processes such as $\mathrm{ZnO} / \mathrm{UV}$, $\mathrm{H}_{2} \mathrm{O}_{2} / \mathrm{UV}$ or $\mathrm{O}_{3} / \mathrm{UV}$ are also not completely effective to remove pollutants in the wastewater ${ }^{2,4}$. Adsorption using activated carbon could adequately eliminate color and COD in the wastewater as the high surface area of activated carbon ${ }^{5}$. However, a complete removal of the organic pollutant in coffee process wastewater required large doses of adsorbent which increments the treating cost both in construction and running ${ }^{6}$. Biological process such as anaerobic digestion has also applied for removing this wastewater ${ }^{7}$. Nonetheless, the finding ${ }^{7}$ also showed that the biodegradation process required both a long treatment time for acclimation and a huge space to set up a biological unit. The removal efficiency also greatly depend on the types of organisms in the biological systems. Hence, those mentioned methods could not be employed to treat real instant coffee processing wastewater.

Recently, a number of investigations have reported that application of electrocoagulation (EC) - a kind of coagulation method- to wastewater treatment have many advantages such as low investment cost, low space requirement, absence or less of additional chemicals, less retention time, less sludge production, simple equipment and easy to operate $\mathrm{e}^{\mathbf{8 - 1 0}}$. In this process, a direct electrical current is used to dissolve metal electrode (mostly iron and aluminum) forming a range of coagulant species and metal hydroxides, which precipitation and adsorption efficiencies are greater than pre-precipitated hydroxides of conventional coagulant like coagulation process ${ }^{11}$. Some studies have successfully applied this technique for the treatment of difference kind of wastewaters including dairy $^{10}$, textile ${ }^{12,13}$, pesticide ${ }^{9}$, herbicide ${ }^{8}$, trace metal ${ }^{14}$, etc. However, research on instant coffee processing wastewater using this technique has not been explored.

Besides the choice of removal techniques, experimental design is also a critical task. Experimental design studies are generally divided into two types: (i) one-factor-at-a-time approach and (ii) multi-response approach. The first was widely used because it is simple i.e. examination the influence of each factor individually on the response. Nonetheless, it has some disadvantages such as high consumption of sample, dissipation of experiment, and not showing interaction between variables ${ }^{15}$. To alleviate these problems, the later - multivariate approaches are widely used. One of the popular multivariate approaches is Response Surface Methodology (RSM) - a collection of statistical and mathematical techniques those are successful for developing, improving, and optimizing processes; interpreting the relationships between responses and factor effects in many treatment processes of wastewater such as textile ${ }^{12,16}$, paint ${ }^{17}$, baker's yeast ${ }^{18}$, etc. ${ }^{19}$. However, the research literature on the application of RSM design for instant coffee production wastewater treatment by EC method is still very limited so far. The objective of this study is to investigate the COD removal of instant coffee wastewater by EC process using RSM. For this purpose, central composite design (CCD) was used with three variables, namely, current density, the electrolysis time and the initial $\mathrm{pH}$.

\section{MATERIAL AND METHODS}

\section{Instant coffee processing wastewater}

The wastewater samples used in this study were collected from an equalization tank of a local instant coffee factory (Vina coffee, Bien Hoa City, Vietnam). 
All samples were stored manually in $20 \mathrm{~L}$ plastic containers, and then transferred, refrigerated, and analysed immediately in accordance with Standard Methods for the Examination of Water and Wastewater ${ }^{20}$. Table 1 shows some characteristics of the wastewater samples.

Table 1. Characterization of raw instant coffee processing wastewater

\begin{tabular}{|l|c|c|}
\hline Parameters & Values & ${ }^{*}$ QCVN 40 (Column B) \\
\hline $\mathrm{pH}$ & $4.9-5.3$ & $5.5-9.0$ \\
\hline $\mathrm{BOD}[\mathrm{mg} / \mathrm{L}]$ & $1.542-3.551$ & 50 \\
\hline Color $[\mathrm{Pt}-\mathrm{Co}]$ & $3.540-4.371$ & 150 \\
\hline $\mathrm{COD}[\mathrm{mg} / \mathrm{L}]$ & $2.820-5.638$ & 150 \\
\hline $\mathrm{TSS}[\mathrm{mg} / \mathrm{L}]$ & $420-618$ & 100 \\
\hline $\mathrm{NH}_{4}{ }^{+}-\mathrm{N}[\mathrm{mg} / \mathrm{L}]$ & $13.6-25.7$ & 10 \\
\hline Total-N [mg/L] & $45-127$ & 40 \\
\hline
\end{tabular}

*Vietnam national technical regulation on industrial wastewater

\section{Electrocoagulation reactor}

All experiments were carried out in a 4-L volume of sample, using a biopolar electrocoagulator (Fig. 1) with four parallel iron plates $(15 \mathrm{~cm}$ width $\times 14.6 \mathrm{~cm}$ height and $0.4 \mathrm{~cm}$ thickness) which were placed $1.5 \mathrm{~cm}$ apart from each other. The outer electrodes were connected to a digital DC power supply ( $220 \mathrm{~V}$ and $30 \mathrm{~A})$ whose poles automatically switch every 30 seconds to minimize electrode encrustation. A valve was installed at the bottom of the reactor to withdraw the precipitated material through a sludge chamber. The detailed electrocoagulation reactor could be found in the previous study of Bui (2016) ${ }^{13}$.

\section{Experimental procedure}

In each run, the 4 liter wastewater containing 8 gram $\mathrm{Na}_{2} \mathrm{SO}_{4}$ anhydrous (as supporting electrolyte) was placed into the electrocoagulator. The $\mathrm{pH}$ of samples was adjusted to the needed $\mathrm{pH}$ values (4-10) by $\mathrm{NaOH}$ or $\mathrm{HCl}(0.1 \mathrm{M})$ solutions. After that, the current density was adjusted to the desired value $\left(43.4-130 \mathrm{~A} / \mathrm{m}^{2}\right)$ at different electrolysis time (4-12 min). After $30 \mathrm{~min}$ settling at the end of each run, $50 \mathrm{~mL}$ of the treated samples were collected and determined Chemical oxygen demand (COD) value by Standard methods for the examination of water and wastewater ${ }^{20}$. Furthermore, to avoid electrode passivation, at the end of each run, the electrodes were washed thoroughly with water and dipped in $0.5 \mathrm{M} \mathrm{HCl}$ solution for at least $15 \mathrm{~min}$ to dissolve any oxide from the electrode surface.

\section{Experimental design and analysis}

The Minitab Software (version 16.2.0) was used to perform statistical design of the experiments and data analysis. The central composite design (CCD) and response surface methodology (RSM) were applied to optimize and assess the relationship among three significant independent variables: (i) Electrolysis time, (ii) Current density, and (iii) initial $\mathrm{pH}$ while COD removal efficiency was considered as the response (dependent factor).

Total 17 experiments consisting of 12 factorial points and 5 replicates at the center point were designed. The level of selected parameters is showed in Table 2 in which the COD removal efficiency is modelled by quadratic expression (Eq. 1) as follow.

$\mathrm{Y}=\mathrm{b}_{0}+\mathrm{b}_{1} \mathrm{X}_{1}+\mathrm{b}_{2} \mathrm{X}_{2}+\mathrm{b}_{3} \mathrm{X}_{3}+\mathrm{b}_{11} \mathrm{X}_{1}^{2}+\mathrm{b}_{22} \mathrm{X}_{2}^{2}+$ $+b_{33} X_{3}^{2}+b_{12} X_{1} X_{2}+b_{23} X_{2} X_{3}+b_{13} X_{1} X_{3}$

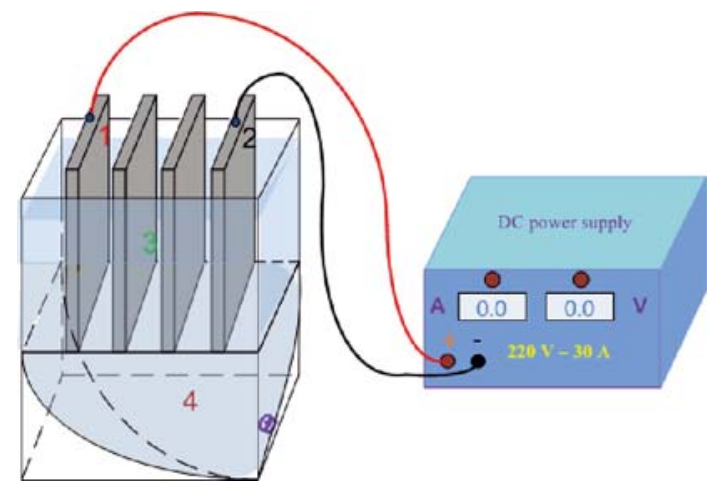

Figure 1. The setup of EC experiment ${ }^{13}$

Where $Y$ is the desired response, $b_{0}, b_{1}, b_{2}, b_{3}, b_{11}$, $b_{22}, b_{33}$, and $b_{12}, b_{23}, b_{13}$ are the regression coefficients to be determined. $\mathrm{X}_{1}, \mathrm{X}_{2}, \mathrm{X}_{3}$ are the coded values of the significant variables: Electrolysis time, current density and initial $\mathrm{pH}$, respectively.

Table 2. Experimental range and levels of independent parameters

\begin{tabular}{|l|l|c|c|c|}
\hline \multirow{2}{*}{ Parameters } & \multicolumn{3}{|c|}{ Levels } \\
\cline { 3 - 5 } & -1 & 0 & 1 \\
\hline Electrolysis time $[\mathrm{min}]$ & $\mathrm{X}_{1}$ & 4 & 8 & 12 \\
\hline Current density $\left[\mathrm{A} / \mathrm{m}^{2}\right]$ & $\mathrm{X}_{2}$ & 43.4 & 86.6 & 130.0 \\
\hline Initial $\mathrm{pH}$ & $\mathrm{X}_{3}$ & 4 & 7 & 10 \\
\hline
\end{tabular}

Analysis of variance (ANOVA) was used for graphical analyses of the data to obtain the interaction between the process variables and the response. The quality of the fit polynomial model was expressed by the value of correlation coefficient $\left(\mathrm{R}^{2}\right)$, and its statistical significance was checked by the $\mathrm{F}$ test. Model terms were evaluated by the $P$ value (probability) with $95 \%$ confidence level.

\section{RESULTS AND DISCUSSION}

\section{Model fitting and validation}

Table 3 presents the ANOVA of regression parameters of the predicted quadratic response surface and other statistical parameters.

As shown in Table 3, the amounts of $P$ values for the model confirmed that the three selected factors are significant $(\leq 0.05)$. However, the high of $P$ values for $X_{1} X_{2}$ and $X_{2} X_{3}$ indicate that the interactions should be eliminated in the final model. Therefore, the reduced model, which describes the response as a function of significant variables, is given below:

$\mathrm{Y}=6.767 \mathrm{X}_{1}+3.372 \mathrm{X}_{2}+3.880 \mathrm{X}_{3}-6.159 \mathrm{X}_{1}^{2}-4.418 \mathrm{X}_{2}^{2}$ $-2.507 \mathrm{X}_{3}^{2}-3.490 \mathrm{X}_{1} \mathrm{X}_{3}-6.043$

The model $\mathrm{F}$ - value of 19.72 implied that the model is significant enough for regression analysis between response and variable effects. The goodness of fit of the model is checked in terms of the determination of regression coefficient $\left(\mathrm{R}^{2}\right)$. The value 0.9621 of $\mathrm{R}^{2}$ indicated that only $3.79 \%$ of the variation around the mean could not be explained by the model. Furthermore, an $\mathrm{R}_{\text {adj }}^{2}(0.9133)$ close to the $\mathrm{R}^{2}$ value and the lack of fit (0.081 - not significant) ensure a satisfactory adjustment of the quadratic models to the experimental data ${ }^{15}$.

Besides numerical method above, in order to obtain an adequate approximation of real system, graphical method was also used to validate the model. Figure 2 
Table 3. Analysis of variance (ANOVA) for COD removal efficiency [\%]

\begin{tabular}{|l|r|r|r|r|r|r|}
\hline Source & DF & Seq SS & Adj SS & Adj MS & F-value & P \\
\hline Model & 9 & 9388.90 & 9388.90 & 1043.21 & 19.72 & 0.000 \\
\hline $\mathrm{X}_{1}$ & 1 & 3414.27 & 2422.67 & 2422.67 & 45.80 & 0.000 \\
\hline $\mathrm{X}_{2}$ & 1 & 953.54 & 601.39 & 601.39 & 11.37 & 0.012 \\
\hline $\mathrm{X}_{3}$ & 1 & 463.91 & 796.32 & 796.32 & 15.05 & 0.006 \\
\hline $\mathrm{X}_{1}{ }^{2}$ & 1 & 2278.27 & 2006.43 & 2006.43 & 37.93 & 0.000 \\
\hline $\mathrm{X}_{2}{ }^{2}$ & 1 & 1098.18 & 1032.54 & 1032.54 & 19.52 & 0.003 \\
\hline $\mathrm{X}_{3}{ }^{2}$ & 1 & 332.54 & 332.54 & 332.54 & 6.29 & 0.041 \\
\hline $\mathrm{X}_{1} \mathrm{X}_{2}$ & 1 & 200.69 & 200.69 & 200.69 & 3.79 & 0.092 \\
\hline $\mathrm{X}_{1} \mathrm{X}_{3}$ & 1 & 644.40 & 644.40 & 644.40 & 12.18 & 0.010 \\
\hline $\mathrm{X}_{2} \mathrm{X}_{3}$ & 1 & 3.10 & 3.10 & 3.10 & 0.06 & 0.816 \\
\hline Residual error & 7 & 370.30 & 370.30 & 52.90 & & \\
\hline Lack of fit & 3 & 370.20 & 370.20 & 123.40 & 4786.63 & 0.081 \\
\hline Pure error & 4 & 0.10 & 0.10 & 0.03 & & \\
\hline Total & 16 & 9759.20 & & & & \\
\hline
\end{tabular}

$R^{2}=0.9621$ and $R_{\text {adj }}^{2}=0.9133$.
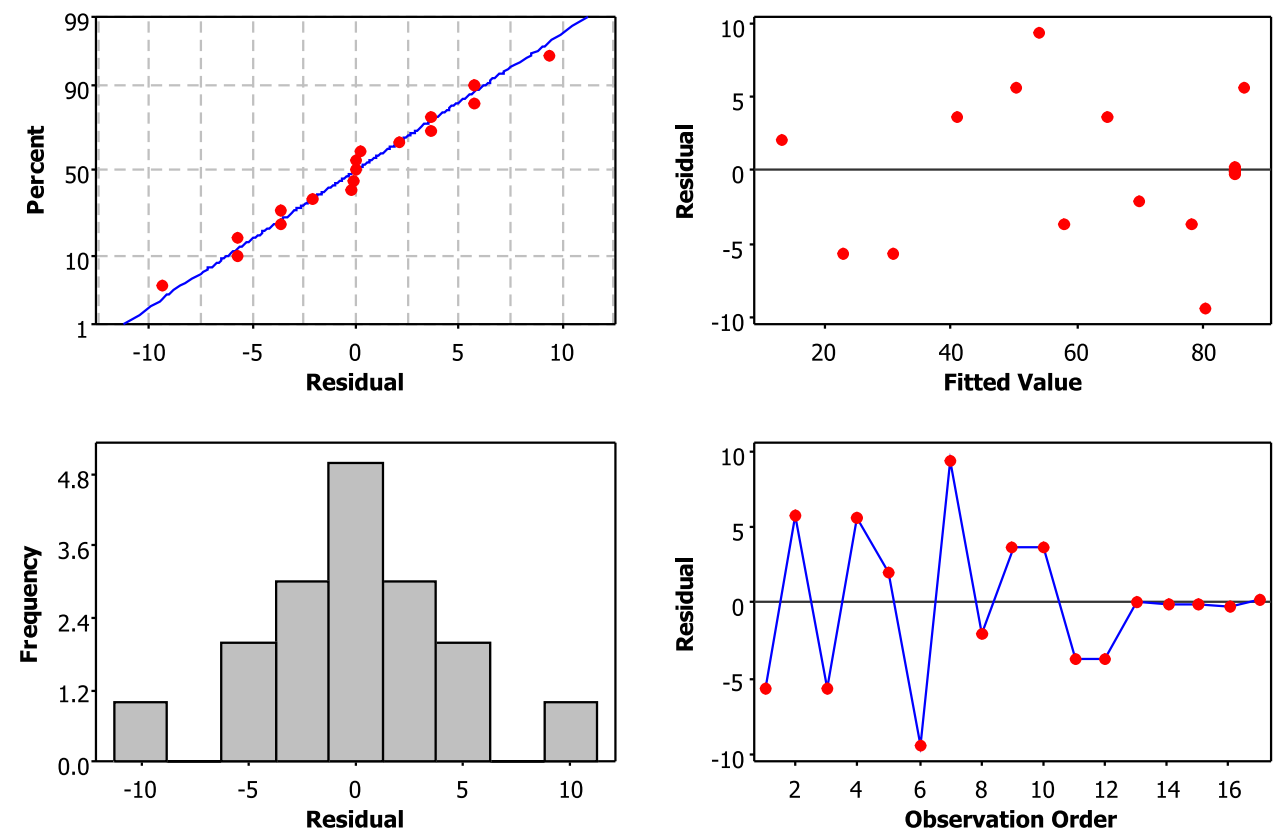

Figure 2. The natural residuals of the model: a) Normal probability plots, b) Residuals vs. fitted values, c) Residual histogram, and d) Residuals vs. observation orders of data

shown the nature of residual of the model. It can be seen that there is no apparent obvious pattern and this is implying the residuals of the model were normal and random distribution. It is plausible that the assumptions of normality were satisfied for the data.

\section{Effects of operating parameters}

The design matrix with experimental and predicted COD removal efficiencies are listed in Table 4. The best observed percent COD removal efficiency was reached $92 \%$ which is higher than $67 \%$ COD case using anaerobic and aerobic process of Selvamurugan et al. (2010) ${ }^{\mathbf{1}}$. The influence of three operating parameters on COD removal efficiency has been analyzed and the results are presented in terms of contour plots. The combined effect of electrolysis time and current density is given in Figure 3. It should be noticed that, at first, the percentage COD removal incremented with both current density and electrolysis time. According to Faraday's law, the dissolution of electrode is directly relative to the current density and electrolysis time ${ }^{18}$. In other words, the increasing in current density or electrolysis time induces more coagulant species which eliminated pollutant in instant coffee processing wastewater. Moreover, the increasing current density or electrolysis time enhance the hydrogen gas generation in the cathode electrode (Eq. 3) which is beneficial for pollutants eliminated by flotation?.

$4 \mathrm{H}_{2} \mathrm{O}+2 \mathrm{e}^{-} \rightarrow 4 \mathrm{OH}^{-}+\mathrm{H}_{2}$

However, as the current density or electrolysis time was reached "suitable" values, the COD removal efficiency was no longer improved. These results should be explained due to the iron coagulant was saturated in the solution and could not react efficiently. The observation is in agreement with other reports ${ }^{\mathbf{9}, 18}$. Therefore, It would be careful found suitable range of the two factors as doing electrocoagulation experiment.

The combined effect of electrolysis time and initial $\mathrm{pH}$ is shown in Figure 4. It can be ascertained that the percentage COD removal increases with increasing the initial $\mathrm{pH}$ from weak acidic to slightly alkaline conditions ( $\mathrm{pH}$ around 5.0-9.0) for given electrolysis time. Further increase in the initial $\mathrm{pH}$ did not show any significant improvement in the percentage COD removal. This is supposed to be due to the formation of various iron hydroxides species at difference $\mathrm{pH}$ values ${ }^{\mathbf{1 6}, \mathbf{2 1}}$. During EC process with iron electrode, at first, ferrous iron ion $\left(\mathrm{Fe}^{2+}\right)$ was produced through anode dissolution as equation (4). At this electrode, the formation of oxygen 
Table 4. Central composite design with observed and predictive response

\begin{tabular}{|c|c|c|c|c|c|}
\hline \multirow[b]{2}{*}{ Run } & \multicolumn{3}{|c|}{ Experimental design } & \multicolumn{2}{|c|}{ COD removal efficiency [\%] } \\
\hline & $\begin{array}{c}\text { Electrolysis time } \\
{\left[\mathrm{X}_{1}\right]}\end{array}$ & $\begin{array}{c}\text { Current density } \\
{\left[\mathrm{X}_{2}\right]}\end{array}$ & $\begin{array}{c}\text { Initial pH } \\
{\left[\mathrm{X}_{3}\right]}\end{array}$ & Experimental & Predicted \\
\hline 1 & -1 & -1 & 0 & 17.2 & 15.9 \\
\hline 2 & +1 & -1 & 0 & 55.9 & 57.2 \\
\hline 3 & -1 & +1 & 0 & 25.0 & 27.8 \\
\hline 4 & +1 & +1 & 0 & 91.9 & 89.1 \\
\hline 5 & -1 & 0 & -1 & 15.4 & 26.0 \\
\hline 6 & +1 & 0 & -1 & 70.6 & 67.3 \\
\hline 7 & -1 & 0 & +1 & 63.3 & 61.2 \\
\hline 8 & +1 & 0 & +1 & 67.8 & 72.5 \\
\hline 9 & 0 & -1 & -1 & 44.7 & 41.0 \\
\hline 10 & 0 & +1 & -1 & 68.3 & 64.6 \\
\hline 11 & 0 & -1 & +1 & 54.3 & 58.0 \\
\hline 12 & 0 & +1 & +1 & 74.5 & 78.1 \\
\hline 13 & 0 & 0 & 0 & 85.0 & 85.0 \\
\hline 14 & 0 & 0 & 0 & 84.9 & 85.0 \\
\hline 15 & 0 & 0 & 0 & 84.9 & 85.0 \\
\hline 16 & 0 & 0 & 0 & 84.8 & 85.0 \\
\hline 17 & 0 & 0 & 0 & 85.2 & 85.0 \\
\hline
\end{tabular}

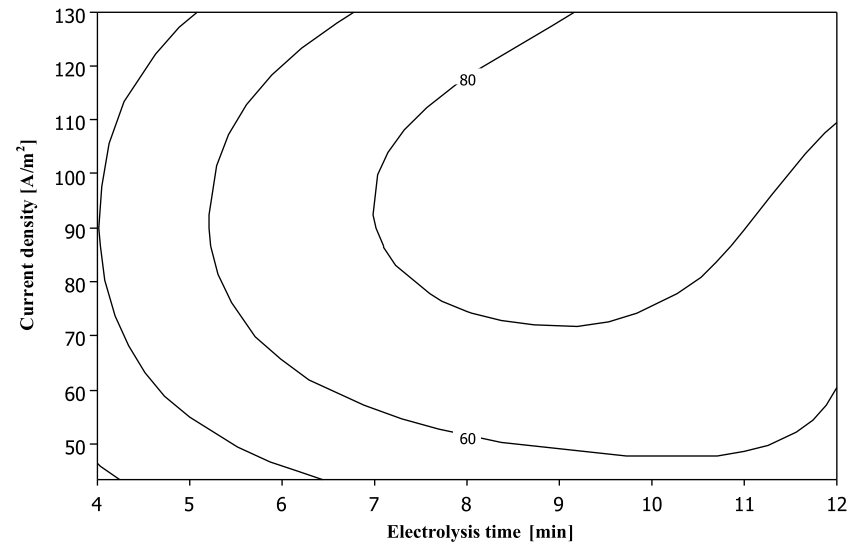

Figure 3. The contour plot of current density and electrolysis time on percentage COD removal at $\mathrm{pH} 7.0$

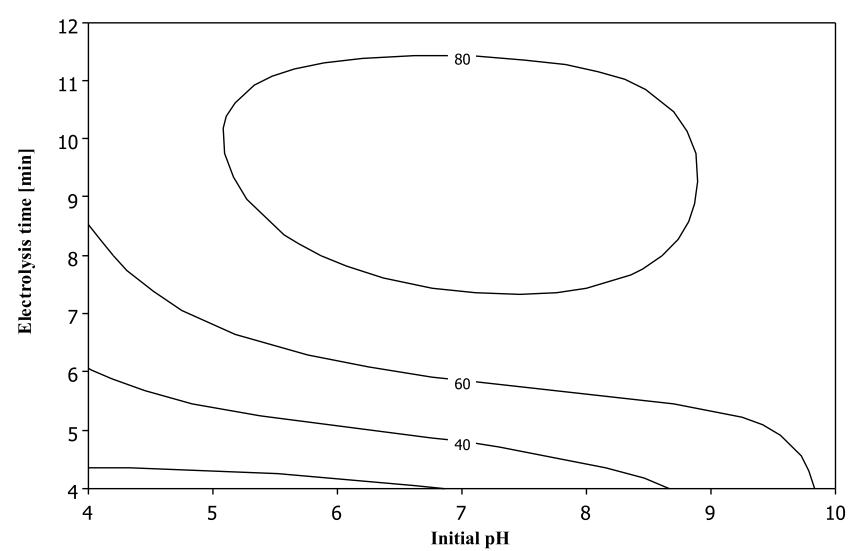

Figure 4. The contour plot of electrolysis time and initial $\mathrm{pH}$ on percentage COD removal at current density $86.6 \mathrm{~A} / \mathrm{m}^{2}$

also occurred through equation (5). At there, ferrous iron ion is reduced to ferric iron ion $\left(\mathrm{Fe}^{3+}\right)$ by oxygen as equation (6). The ferric iron ion further reacts with hydroxide ions to form $\mathrm{Fe}(\mathrm{OH})_{3}$, subsequently the equation (6) should be rewritten to equation (7).

$2 \mathrm{Fe} \rightarrow 2 \mathrm{Fe}^{2+}+4 \mathrm{e}^{-}$

$2 \mathrm{H}_{2} \mathrm{O} \rightarrow \mathrm{O}_{2}+4 \mathrm{H}^{+}+4 \mathrm{e}^{-}$

$2 \mathrm{Fe}^{2+}+1 / 2 \mathrm{O}_{2}+\mathrm{H}_{2} \mathrm{O} \rightarrow 2 \mathrm{Fe}^{3+}+2 \mathrm{OH}^{-}$

$2 \mathrm{Fe}^{2+}+1 / 2 \mathrm{O}_{2}+5 \mathrm{H}_{2} \mathrm{O} \rightarrow 2 \mathrm{Fe}(\mathrm{OH})_{3(\mathrm{~s})}+4 \mathrm{H}^{+}$
An explanation for the trend could be found in the report of Barrera-Díaz, et al. $(2003)^{\mathbf{2 1}}$, who stated that the kind of ferrous iron hydroxides species on EC process was crucially influenced by solution's $\mathrm{pH}$. The highest COD removal result was obtained at $\mathrm{pH}$ range 6.0-9.0 may be due to the formation of $\mathrm{Fe}(\mathrm{OH})_{3}$ (s) flocs which have large surface areas. These flocs are useful for a rapid adsorption of soluble organic pollutant in instant coffee processing wastewater. At other $\mathrm{pH}$ values, the complexes of formed iron hydroxide products such as: $\mathrm{Fe}(\mathrm{OH})_{2}{ }^{+}$, $\mathrm{Fe}(\mathrm{OH})^{2+}, \mathrm{Fe}(\mathrm{OH})_{4}^{-}$, etc. caused the decrease in the removal efficiencies.

The findings in this study also correlate well with the results presented by Daneshvar, et al. (2007) ${ }^{16}$ who reported that the best $\mathrm{pH}$ ranges for discoloration efficiency of Acid Yellow 23 were from 5.0 to 9.0.

A similar trend was observed as changing current density vs initial $\mathrm{pH}$. Figure 5 indicated that the removal was peak (greater than $80 \%$ ) as wastewater is in $\mathrm{pH}$ medium around 6.0-9.0 and current density in range $75-110 \mathrm{~A} / \mathrm{m}^{2}$. At other ranges of $\mathrm{pH}$ or current density, the COD removal sharply decrease. The high removal at near neutral $\mathrm{pH}$ can be explained by the formation of $\mathrm{Fe}(\mathrm{OH})_{3}(\mathrm{~s})$ flocs which have a good coagulation effect ${ }^{22}$. While the initial increasing and then decreasing COD removal trend with the incrementing current density

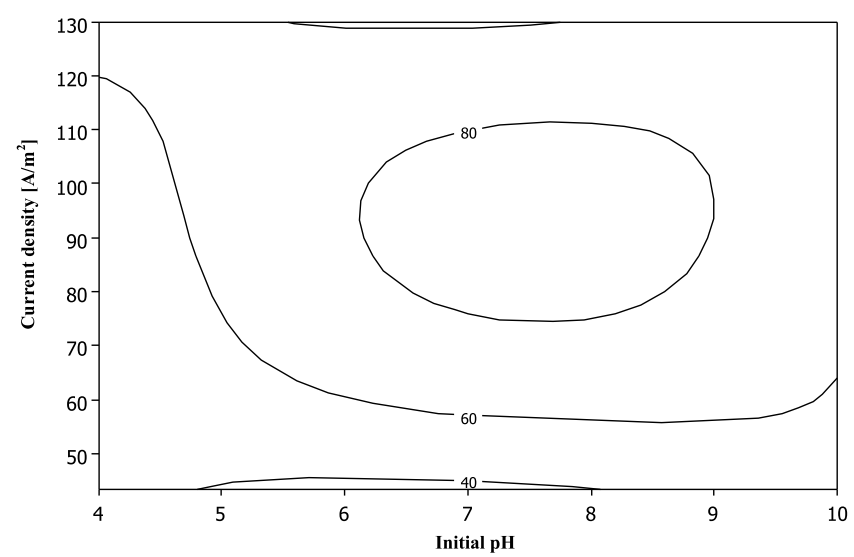

Figure 5. The contour plot of current density and initial $\mathrm{pH}$ on percentage COD removal at electrolysis time $8 \mathrm{~min}$ 
could be explained by Faraday's law and the saturated effect of iron coagulant ${ }^{18}$.

\section{Optimization process}

In order to achieve the optimum point by EC process, the desired COD removal efficiency was defined as target to achieve $100 \%$ while each operational condition (electrolysis time, current density, and initial $\mathrm{pH}$ ) was chosen "within" the range. Then, the program (Minitab) searched to optimize function based on the response goal. Accordingly, the optimization result for the maximum COD removal efficiency was $93.3 \%$ with electrolysis time 10 min, current density $108.3 \mathrm{~A} / \mathrm{m}^{2}$ and initial $\mathrm{pH} 7.0$ with the desirability function value was found to be 0.925 for the treatment of instant coffee processing wastewater. Two additional experiments were then performed to verify the optimum results. The average COD removal value obtained through the experiment was $90.4 \%$ which agreed well with the predicted response value.

\section{CONCLUSION}

RSM could be considered as a possible technique for modeling the COD removal in the treatment of instant coffee processing wastewater using electrocoagulation. On the electrocoagulation treatment process, the COD removal efficiency was found to be function of the initial $\mathrm{pH}$, current density and electrolysis time as well as their squares and their interactions. Both graphical (residual plots) and numerical method (high in $\mathrm{R}^{2}, \mathrm{R}^{2}$ adj , F-value) verified that the accuracy of the Minitab proposed polynomial model is acceptable. Based on the results, the COD removal process was favored at near neutral media (initial $\mathrm{pH}$ around 6.0-9.0). At the initial $\mathrm{pH}$ range, a higher current density or a longer electrolysis time gave a higher COD abatement. The optimum COD removal efficiency was found $93.3 \%$ with electrolysis time of $10 \mathrm{~min}$, current density of $108.3 \mathrm{~A} / \mathrm{m}^{2}$ and initial $\mathrm{pH}$ of 7.0. The optimum condition could be also verified by additional experiments at the optimum condition, the result is in close agreement $(90.4 \%)$.

\section{LITERATURE CITED}

1. Selvamurugan, M., Doraisamy, P. \& Maheswari, M. (2010). An integrated treatment system for coffee processing wastewater using anaerobic and aerobic process. Ecol. Eng. 36, 1686-1690. DOI: 10.1016/j.ecoleng.2010.07.013.

2. Zayas, T.P., Geissler, G. \& Hernandez, F. (2007). Chemical oxygen demand reduction in coffee wastewater through chemical flocculation and advanced oxidation processes. J. Environ. Sci. 19, 300-305. DOI: 10.1016/S1001-0742(07)60049-7.

3. Al-Mutairi, N.Z. (2006). Coagulant toxicity and effectiveness in a slaughterhouse wastewater treatment plant. Ecotoxicol. Environ. Saf. 65, 74-83. DOI: 10.1016/j.ecoenv.2005.05.013.

4. Satori, H. \& Kawase, Y. (2014). Decolorization of dark brown colored coffee effluent using zinc oxide particles: The role of dissolved oxygen in degradation of colored compounds. J. Environ. Manage. 139, 172-179. DOI: 10.1016/j. jenvman.2014.02.032.

5. Hang, Y.D. \& Woodams, E.E. (1979). A Process for the Removal of Coffee Color from Wastewater. J. Food Sci. 44, 246-247. DOI: 10.1111/j.1365-2621.1979.tb10052.x.

6. Devi, R. (2010). Innovative Technology of COD and BOD Reduction from Coffee Processing Wastewater Using Avocado
Seed Carbon (ASC). Water, Air, Soil Pollut. 207, 299-306. DOI: 10.1007/s11270-009-0137-2.

7. Qiao, W., Takayanagi, K., Shofie, M., Niu, Q., Yu, H.Q. \& Li, Y.Y. (2013). Thermophilic anaerobic digestion of coffee grounds with and without waste activated sludge as co-substrate using a submerged AnMBR: System amendments and membrane performance. Bioresour. Technol. 150, 249-258. DOI: 10.1016/j.biortech.2013.10.002.

8. Benincá, C., Vargas, F.T., Martins, M.L., Gonçalves, F.F., Vargas, R.P., Freire, F.B. \& Zanoelo, E.F. (2016). Removal of clomazone herbicide from a synthetic effluent by electrocoagulation. Water Sci. Technol. 73, 2944-2952. DOI: 10.2166/ wst.2016.133.

9. Abdel, S.G.A., Baraka, A.M., Omran, K.A. \& Mokhtar, M.M. (2012). Removal of Some Pesticides from the Simulated Waste Water by Electrocoagulation Method Using Iron Electrodes. Int. J. Electrochem. 7, 6654-6665.

10. Aitbara, A., Cherifi, M., Hazourli, S. \& Leclerc, J.P. (2016). Continuous treatment of industrial dairy effluent by electrocoagulation using aluminum electrodes. Desalin. Water. Treat. 57, 3395-3404. DOI: 10.1080/19443994.2014.989411.

11. Mollah, M.Y.A., Morkovsky, P., Gomes, J.A.G., Kesmez, M., Parga, J. \& Cocke, D.L. (2004). Fundamentals, present and future perspectives of electrocoagulation. J. Hazard. Mater. 114, 199-210. DOI: 10.1016/j.jhazmat.2004.08.009.

12. Moradi, M., Eslami, A. \& Ghanbari, F. (2016). Direct Blue 71 removal by electrocoagulation sludge recycling in photo-Fenton process: response surface modeling and optimization. Desalin. Water. Treat. 57, 4659-4670. DOI: 10.1080/19443994.2014.995714.

13. Bui, H.M. (2016). Modeling the removal of Sunfix Red S3B from aqueous solution by electrocoagulation process using artificial neural network. J. Serb. Chem. Soc. 81, 959-974. DOI: 10.2298/JSC160108032M.

14. Heffron, J., Marhefke, M. \& Mayer, B.K. (2016). Removal of trace metal contaminants from potable water by electrocoagulation. Sci. Rep. 6, 1-9. DOI: 10.1038/srep28478.

15. Montgomery, D.C., Design and Analysis of Experiments, Eighth ed., John Wiley \& Sons, Inc., United States, 2013.

16. Daneshvar, N., Khataee, A.R., Amani Ghadim, A.R. \& Rasoulifard, M.H. (2007). Decolorization of C.I. Acid Yellow 23 solution by electrocoagulation process: Investigation of operational parameters and evaluation of specific electrical energy consumption (SEEC). J. Hazard. Mater. 148, 566-572. DOI: 10.1016/j.jhazmat.2007.03.028.

17. Körbahti, B.K., Aktaş, N. \& Tanyolaç, A. (2007). Optimization of electrochemical treatment of industrial paint wastewater with response surface methodology. J. Hazard. Mater. 148, 83-90. DOI: 10.1016/j.jhazmat.2007.02.005.

18. Gengec, E., Kobya, M., Demirbas, E., Akyol, A. \& Oktor, K. (2012). Optimization of baker's yeast wastewater using response surface methodology by electrocoagulation. Desalination 286, 200-209. DOI: 10.1016/j.desal.2011.11.023.

19. Khayet, M., Zahrim, A.Y. \& Hilal, N. (2011). Modelling and optimization of coagulation of highly concentrated industrial grade leather dye by response surface methodology. Chem. Eng. J. 167, 77-83. DOI: 10.1016/j.cej.2010.11.108.

20. Federation, W.E. \& American Public Health, A., Standard methods for the examination of water and wastewater, American Public Health Association (APHA), 2005.

21. Barrera-Díaz, C., Palomar-Pardavé, M., Romero-Romo, M. \& Martínez, S. (2003). Chemical and electrochemical considerations on the removal process of hexavalent chromium from aqueous media. J. Appl. Electrochem. 33, 61-71. DOI: 10.1023/A:1022983919644. 